\section{Studies on Some New Thiazolidones as Potential Fungicides}

\author{
Radhey SHYAM and I. C. TIWARI
}

\begin{abstract}
Department of Chemistry, Faculty of Science, Banaras Hindu University, Varanasi-221005, India
\end{abstract}

Received April 9, 1974

There are several reports on 2,3-(disubstituted)-4thiazolidones as local anaesthetics, ${ }^{11}$ antibacterials ${ }^{2 !}$ and antifungal agents. ${ }^{3}$ Bhargava et al. have shown some thiazolidones and their derivatives screened as fungicides. ${ }^{4,5}$ Antifungal activity against Alternaria tenuis and Botrytis allii by Matolcsy et al. ${ }^{61}$ and against Helminthosporium euphorbiae by Srivastava ${ }^{7}$ was tested for thiazolidones and found to be sufficient active.

On the basis of the above findings we have synthesized some 3-benzyl-(or $p$-tolyl)-5-methyl-2-(substituted-benzothiazol-2'-ylimino)-4-thiazolidones by the interaction of $\mathrm{N}$-benzyl (or $p$-tolyl)- $\mathrm{N}^{\prime}$-(substituted)benzothiazol-2-yl thiocarbamides with $\alpha$-chloropropionic acid in anhydrous condition. These thiazolidones were screened against the fungus Alternaria tenuis by Agargrowth method at concentrations $1: 1000,1: 5000$ and $1: 10,000$. The percentage inhibition in growth by an inhibitor at a particular concentration is determined by comparison with the growth in controls (i.e., untreated petridishes) and the results are recorded in Table II.

Table II. Fungicidal Activity of 3-Benzyl (OR $p$-TOLYL)-5-METHYL-2-(SUBSTITUTED-

BENZOTHIAZOL-2'-YLIMINO)-4-THIAZOLIDONES

Control: $42 \mathrm{~mm}, 44.5 \mathrm{~mm}$ and $45.5 \mathrm{~mm}$ at concentrations $1: 1,000,1: 5,000$ and $1: 10,000$ respectively. Temperature, $25 \sim 30^{\circ} \mathrm{C}$; Fungus, Alternaria tenuis; Time, 6 days; Medium, Czapek's agar.

\begin{tabular}{|c|c|c|c|}
\hline \multirow{2}{*}{ S.No. ${ }^{a)}$} & \multicolumn{3}{|c|}{ Percentage inhibition of concentration } \\
\hline & $1: 1,000$ & $1: 5,000$ & $1: 10,000$ \\
\hline 1 & 28.6 & 40.5 & 42.9 \\
\hline 3 & 100 & 100 & 100 \\
\hline 4 & 100 & 49.5 & 7.7 \\
\hline 5 & 17.9 & 35.9 & 38.5 \\
\hline 6 & 76.4 & 23.8 & 7.7 \\
\hline 8 & 93.1 & 88.1 & 37.1 \\
\hline 9 & 100 & 90.1 & 40.9 \\
\hline
\end{tabular}

a) S.No, corresponds to the serial number of the compounds in Table I.

It is evident that the compound 3-benzyl-5-methyl-2(4'-chlorobenzothiazol-2'-ylimino)-4-thiazolidone in- hibits $100 \%$ spore germination of the fungus at all the three concentrations. Antifungal potency is being found to be increased by halogen substituents. It is also evident that the activity is being decreased with the increase in dilution.

All melting points were taken by the capillary method and are uncorrected. The purity of the compounds was tested by thin-layer chromatography. A Varian A60D model was used for recording of NMR spectra, Perkin Elmer-257 for IR and a Coleman Analyzer for analyses.

$N$-Benzyl-N'-5-methylbenzothiazol-2-yl thiocarbamide. A mixture of 5-methyl-2-aminobenzothiazole $(4.1 \mathrm{~g})$, benzyl isothiocyanate $(3.7 \mathrm{ml})$ and dry benzene $(40 \mathrm{ml})$ was refluxed on a water-bath with occasional shaking for about $5 \mathrm{hr}$ at $80 \sim 90^{\circ} \mathrm{C}$. The residue was filtered under suction and washed successively with ether and $40 \% \mathrm{HCl}$ solution. The product was crystallised from ethanol, yield $76 \%$ mp $192^{\circ} \mathrm{C}$. TLC: $R f=0.82$ (benzene-ether, 3:1). Anal. Calcd. for $\mathrm{C}_{16} \mathrm{H}_{15} \mathrm{~N}_{3} \mathrm{~S}_{2}$ : $\mathrm{N}, 13.42 ; \mathrm{S}, 20.45$. Found: N, 13.39; S, 20.56 . IR $v_{\max }^{\mathrm{nujol}} \mathrm{cm}^{-1}: 3175 \mathrm{~s}(\mathrm{NH}), 3075(>\mathrm{NH}), 1565 \mathrm{~s}(\mathrm{C}=\mathrm{N}-$ or $>\mathrm{C}=\mathrm{C} 0,1210 \bigcirc \mathrm{C}=\mathrm{S}) . \quad \mathrm{NMR}\left(\mathrm{CDCl}_{3}\right) \delta(J=\mathrm{Hz})$ : $2.48(3 \mathrm{H}, \mathrm{s})$ for benzene ring methyl protons, 5.08 $(2 \mathrm{H}, \mathrm{d}, J=5.0)$ for aromatic protons, $7.80(1 \mathrm{H}$, broad) and $10.95(1 \mathrm{H}$, broad $)$ for two $>\mathrm{NH}$ bonds.

Similarly, other 2-amino-(substituted)benzothiazoles were converted into their respective thiocarbamides by treating with benzyl isothiocyanate and $p$-tolyl isothiocyanate.

3-Benzyl-5-methyl-2-(5'-methylbenzothiazol-2'-ylimino)4-thiazolidone. N-Benzyl-N'-5-methylbenzothiazol2-yl thiocarbamide $(3.13 \mathrm{~g})$ was dissolved in absolute alcohol $(35 \mathrm{ml})$ and $\alpha$-chloropropionic acid $(1.5 \mathrm{ml})$ as well as anhydrous sodium acetate $(2.5 \mathrm{~g})$ were added to this. The mixture was refluxed on a water-bath for $8 \sim 10 \mathrm{hr}$ and then poured into ice-cooled water. On keeping overnight, the solid mass was obtained. It was filtered and washed several times with hot water. The dried product was crystallised from ethanol into shining needles, yield $80 \%, \mathrm{mp} 201^{\circ} \mathrm{C}$. TLC: $R f=$ 0.84(benzene-ether, 3: 1). Anal. Calcd. for $\mathrm{C}_{19} \mathrm{H}_{17} \mathrm{~N}_{3} \mathrm{OS}_{2}$ : $\mathrm{N}, 11.44 ; \mathrm{S}, 17.44$. Found: $\mathrm{N}, 11.41 ; \mathrm{S}, 17.56$. $\mathrm{IR} \nu_{\max }^{\mathrm{nujol}} \mathrm{cm}^{-1}: 1720 \mathrm{~s}(>\mathrm{C}=\mathrm{O}), 1552 \mathrm{~s}(\mathrm{C}=\mathrm{N}-$ or $>\mathrm{C}=\mathrm{C}() . \quad \mathrm{NMR}\left(\mathrm{CDCl}_{3}\right) \delta(J=\mathrm{Hz}): 2.75(3 \mathrm{H}, \mathrm{s})$ for benzene ring methyl protons, $1.75(3 \mathrm{H}, \mathrm{d}, J=7.5)$ for thiazolidone ring methyl protons, $4.17(1 \mathrm{H}, \mathrm{q}, J=7.5)$ for thiazolidone ring single proton, $5.21(2 \mathrm{H}, \mathrm{s})$ for benzyl methylene protons and $8.25(8 \mathrm{H}, \mathrm{m})$ for aromatic protons.

Following the same procedure, other 3-benzyl (or $p$-tolyl)- 5 -methyl-2 -(substituted benzothiazol-2'-ylimino)-4-thiazolidones were synthesized by condensing the respective thiocarbamides with $\alpha$-chloropropionic acid. The structures and the purity of the compounds are recorded in Table $\mathrm{I}$. 

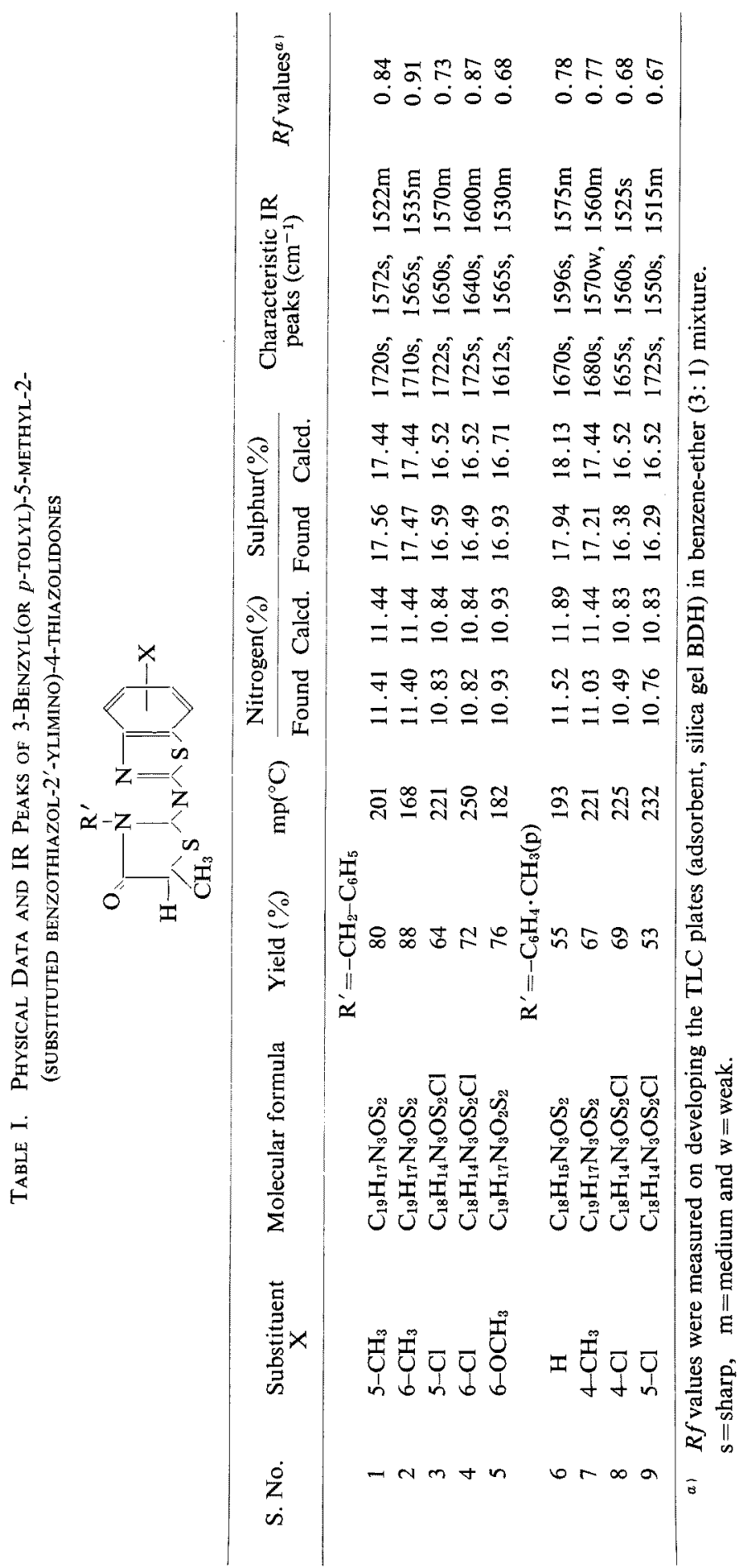
Thanks are due to Prof. P. N. Bhargava, for his keen interest and Prof. G. B. Singh, Dr. R. S. Dwivedi and Sri B. M. Singh for providing facilities. The assistance provided by CSIR, New Delhi to R. S. and by PGIIM, B.H.U. to I.C.T. is gratefully acknowledged.

\section{REFERENCES}

1) A. R. Surrey, J. Am. Chem. Soc., 71, 3105 (1949).

2) M. K. Rout and H. K. Pujari, J. Sci. Ind. Research (India), 14, 448 (1955).
3) H. Tripathy, R. N. Dash, B. C. Dash and G. N. Mahapatra, Indian J. Chem., 9, 1232 (1971).

4) P. N. Bhargava and G. C. Singh, J. Ind. Chem. Soc., 45, 32 (1968).

5) P. N. Bhargava and M. R. Chaurasia, J. Chem. $U A R, 12,149$ (1969).

6) G. Matolcsy, B. Bordash and M. Hamran, Acta Phytopathol., 4, 345 (1969).

7) K. S. L. Srivastava, Indian J. Appl. Chem., 32, 369 (1969). 